\title{
Habilidades Perceptuais entre a Captura e o Comércio de Pescado
}

\author{
Gabriel Coutinho Barbosa ${ }^{1}$ \\ Viviane Vedana ${ }^{1}$ \\ Rafael Victorino Devos ${ }^{1}$
}

${ }^{1}$ Universidade Federal de Santa Catarina, Florianópolis, SC, Brasil

\begin{abstract}
Resumo
O artigo analisa habilidades perceptuais praticadas no mar, na praia ou no mercado para encontrar, capturar e avaliar qualidades de pescado. Para entendermos parte das relações que se estabelecem entre pessoas e peixes entre a captura, a conservação e a comercialização nesses ambientes, acionamos conceitos antropológicos ligados à percepção ambiental e às técnicas do corpo. Refletimos sobre práticas da pesca artesanal que revelam relações ecológicas e qualidades sensíveis que se materializam nas transformações vividas por cardumes de tainhas, ciobas e outros peixes. Com base em pesquisa etnográfica com pescadores artesanais no Sul e no Nordeste do Brasil e com comerciantes de pescado nessas localidades e no entreposto comercial da Companhia de Entrepostos e Armazéns Gerais de São Paulo (CEAGESP), em São Paulo, o artigo contribui para as discussões em torno da constituição de uma Antropologia da Percepção.
\end{abstract}

Palavras-chave: Percepção. Pesca. Técnicas do Corpo. Tainha. Comércio de Pescado.

\section{Perceptual Skills in Fish Catching and Trade}

\begin{abstract}
This article discusses perceptual skills to find, catch and evaluate the quality of fish, practiced at the sea and the beach and in the marketplace. In order to understand relationships between people and fish during the catch, conservation and trade, we made use of concepts linked to the perception of the environment and the techniques of the body. The small-scale fisheries practices reveal ecological relations and sensible qualities embodied through the transformations lived by mullet and mutton snapper schools, among other fish. Based on ethnographic research with fishers in South and Northeast Brazil and fishmongers in the wholesale market CEAGESP, in São Paulo, this article contributes to the debates on the development of an anthropology of perception.
\end{abstract}

Keywords: Perception. Fishing. Techniques of the Body. Mullet. Fish Trade. 


\section{Introdução}

$\mathrm{O}$ pescado na pesca marítima artesanal é o mesmo peixe capturado na pesca industrial? Tratando-se de peixes criados em cativeiro, o manejo de certos fatores ambientais pode provocar diferenças entre populações. Tais variações ambientais e seus efeitos são mais difíceis de se observar nas espécies que em seu ciclo de vida atravessam paisagens litorâneas. Sendo de uma mesma espécie, capturada na mesma região costeira, poderíamos dizer que é o mesmo peixe que chega aos pescadores de pequena ou de grande escala. No entanto, se prestarmos atenção nas técnicas de captura, temos já uma pista para conhecer transformações pelas quais os peixes passam em seus ciclos de vida e ao se tornarem pescado.

Após a captura, outras transformações podem ocorrer. Revelam-se, ou ocultamse, muitas outras qualidades do peixe no comércio - o nome genérico da espécie, a denominação de procedência, as condições ambientais da captura, a técnica de conservação e outras qualidades observadas quanto à temporalidade da safra de pesca ou com relação ao ciclo de vida do peixe. Essas não são qualidades arbitrárias atribuídas a um recurso natural, mas diferenças materializadas em processos técnicos e em relações multiespécies reveladas por habilidades perceptuais.

Com base em pesquisa etnográfica com pescadores artesanais e com comerciantes de pescado, analisaremos algumas dessas transformações e as habilidades necessárias para conhecê-las, praticadas no mar, na praia ou no mercado. Para entendermos parte das relações que se estabelecem entre pessoas e peixes nesses ambientes, acionaremos conceitos antropológicos ligados à percepção e às técnicas do corpo, refletindo como as práticas na percepção ambiental da pesca artesanal revelam relações ecológicas observadas nas qualidades do pescado.

As pesquisas partem de três práticas diferentes seguindo algumas espécies de peixes costeiros. Em Florianópolis, Santa Catarina, buscamos compreender como os vigias da pesca da tainha (Mugil liza) "veem peixes" (DEVOS; VEDANA; BARBOSA, 2016; DEVOS; BARBOSA; VEDANA, 2015; 2019) e orientam sua captura com redes de arrasto na praia. No Nordeste do Brasil, nas praias de Touros (RN) e na Baía da Traição (PB), nossa atenção se volta para as técnicas de navegação de jangadeiros para encontrar "pesqueiros" de ciobas (Lutjanus analis), dentões (Lutjanus locu) ariocós (Lutjanus synagris) e outras espécies menores no mar (BARBOSA; DEVOS, 2017a; 2017b). Nesses locais de pesquisa, observamos formas de comercialização do pescado circulando localmente entre redes de vizinhança e pequenos comerciantes, ou seguindo por meio de intermediários para centros de abastecimento como a Companhia de Entrepostos e Armazéns Gerais 
de São Paulo (CEAGESP), em São Paulo, onde também fazemos pesquisa de campo. Nossa abordagem ${ }^{1}$ parte do campo da antropologia da técnica, articulando discussões sobre a percepção do ambiente e a paisagem, sobre as técnicas envolvidas nas práticas de pesca e também de comercialização.

\section{2 "Ver Peixe": os vigias da pesca da tainha}

Entre os meses de maio e julho, em Florianópolis, Santa Catarina, podemos observar a intensa movimentação das parelhas, que são os coletivos de pesca da tainha envolvidos na modalidade conhecida como "cerco (ou arrasto) de praia" e formados por pescadores, canoa(s), rede(s) e demais apetrechos (DEVOS; VEDANA; BARBOSA, 2016; DEVOS; BARBOSA; VEDANA, 2015; 2017; 2019).

A prática dos vigias tem um papel fundamental nessa modalidade de pesca. Distribuídos ao longo da costa, na beira da praia, em dunas, pedras e encostas de morros, os vigias observam atentamente o mar e outros sinais do ambiente. A eles, cabe: (1) notar a presença dos cardumes de tainhas na costa; (2) diferenciá-los de outros peixes, como anchovas (Pomatomus saltatrix), manjubas (Anchoa lyolepis), paratis (Mugil curema) e bonitos (Sarda sarda); (3) estimar a sua quantidade, a direção e a velocidade em que seguem para, assim; (4) orientar todos os demais camaradas de pesca quanto à velocidade e sobre o trajeto a percorrer com a canoa no movimento do cerco, bem como quanto à disposição da rede a ser lançada ao mar e puxada na praia.

Nossa aproximação a essa prática nos levou a formular duas questões iniciais correlacionadas. Se o porquê de os vigias fazerem o que fazem nos parecia evidente, restavanos saber como fazem o que fazem. A primeira questão que daí surgiu, e que podemos considerar como uma questão etnográfica, foi: como os vigias reconhecem a presença dos peixes, sua quantidade e movimento em tais circunstâncias, enquanto pessoas não familiarizadas com tal prática, como nós, não veem mais do que água, ondas, sombras e reflexos do sol? A segunda questão, que desta decorre, e que podemos dizer é mais teórica, foi: como essa habilidade dos vigias nos ajuda a refletir sobre o modo como a Antropologia tem pensado os fenômenos de percepção? Afinal, é isso que os vigias fazem: percebem a presença dos cardumes de tainhas.

A técnica da pesca de cerco na praia, no litoral Sul do Brasil, consiste em cercar um cardume de tainhas enquanto esse cardume cruza as águas próximo à praia. Com uma canoa a remo, os pescadores movem-se na direção contrária ao movimento do cardume, formando um semicírculo no mar. Tendo uma ponta da rede em terra, à medida em que a canoa avança, lançam a rede (que chega a ter mais de mil metros de comprimento) até retornarem à praia para puxar, então, ambas as pontas da rede. Para que a rede

\footnotetext{
Neste paper, que decorre de nossa apresentação na Mesa "Movimento, percepções e práticas" que ocorreu na VII Reunião de Antropologia da Ciência e da Técnica" em Florianópolis, Santa Catarina, em 2019, pretendemos apresentar algumas das nossas inquietações a respeito das relações entre percepção, técnicas corporais e conhecimento. Não poderíamos também deixar de reconhecer que muitas das ideias que serão aqui desenvolvidas são fruto dos processos de orientação de alunos e alunas cujas pesquisas navegam por essas mesmas preocupações e são discutidas no grupo de pesquisa Coletivo de Pesquisa em Ambientes, Percepções e Práticas (CANOA) do PPGAS UFSC. Agradecemos aos colegas do CANOA pelas contribuições e ao Instituto Nacional de Pesquisas Brasil Plural (INCT IBP PPGAS UFSC) pelo apoio recebido para as pesquisas.
} 
envolva o cardume é preciso acompanhar seus movimentos e antecipar o momento em que o cardume se direciona a uma parte da praia em que possa ser cercado, com tempo suficiente para que a canoa complete o percurso inverso.

Apesar da importância do que fazem para esse tipo de pesca, os vigias e demais pescadores nos forneciam explicações muito breves sobre como "ver peixe". Apontavam com os dedos e descreviam a que deveríamos estar atentos: alguns peixes saltando a alguns metros de distância, a presença e o comportamento de golfinhos e aves marinhas, manchas na água, mudanças nos padrões de movimento e reflexo em sua superfície. A partir desses sinais, bons vigias podem aferir com relativa precisão a espécie de peixes no cardume (tainhas, anchovas, paratis, bonitos), a quantidade de peixes (centenas ou milhares) e a direção de seu movimento. Dessas qualidades dos cardumes avistados, e com base nas notícias de capturas de tainhas em outras praias e mares (DEVOS; BARBOSA; VEDANA, 2019), passavam a outras observações sobre as diferenças que observam a cada temporada de pesca, ou safra, no que diz respeito ao comportamento das tainhas, a mudanças em seu ciclo de vida e a suas relações com as condições atmosféricas e com as atividades de embarcações e de outros animais ao longo da costa.

Os pescadores artesanais conhecem bem certos aspectos do ciclo de vida das tainhas, sobretudo, a sua migração reprodutiva. A partir de abril, a chegada de massas de ar frio antárticas na costa sudeste da América do Sul altera as temperaturas da água e da atmosfera, bem como a direção de ventos e correntes marinhas predominantes. Tais mudanças são acompanhadas por alterações no metabolismo e comportamento das tainhas, que deixam as lagoas e estuários onde se desenvolveram e alimentaram desde juvenis para reproduzir no mar, formando grandes cardumes enquanto migram para o Norte, ao longo do litoral da Argentina, Uruguai e dos estados do Rio Grande do Sul, Santa Catarina, Paraná, São Paulo e Rio de Janeiro, no Brasil2 ${ }^{2}$ Esse processo é observado em detalhes, em suas variações diárias, conforme as mudanças nos ventos e correntes marinhas, que podem aproximar ou afastar os peixes de cada praia, ou nos demais eventos que podem dispersar os cardumes e os direcionarem a novos pontos da costa. As tainhas que cada praia captura trazem inscritas em seu corpo essa história de movimentos da safra. Essas qualidades sensíveis das tainhas se concretizavam ao vermos os peixes na rede, na areia da praia e nas cozinhas: gradas (grandes, com bastante carne e gordura), ovadas (fêmeas com ovas), leiteiras (machos com gônadas esbranquiçadas), baetas (marcadas por outras redes), facão (magras, já retornando após bastante tempo no mar), pequenas e de começo de safra (com gosto de lama e/ou adocicado por terem deixado há pouco a vida nas lagoas), ou repolhudas (pela presença das ovas dispersas nas escamas, indicando já o fim da temporada), para citar algumas possibilidades ${ }^{3}$.

Essas qualidades, confirmadas no trato com o pescado, eram estimadas na observação diária do mar e das notícias dos demais coletivos de pesca. Logo, tornou-se evidente durante o trabalho de campo que não poderíamos privilegiar entrevistas e análises de

\footnotetext{
A fecundação acontece na água, com fêmeas e machos expelindo suas gônadas no mar. Levadas pelas correntes, as larvas se desenvolvem próximo à entrada de lagoas e estuários, para onde os juvenis são recrutados alguns meses após a temporada (LEMOS et al., 2014).

3 Conhecemos na prática da vigia, em nossa pesquisa, categorias semelhantes às que são relatadas por Herbst e Hanazaki (2014) em pesquisa com coletivos de pesca no litoral de Santa Catarina a respeito de seus conhecimentos sobre o ciclo de vida da Mugil liza.
} 
relatos para nos aproximarmos da percepção do ambiente destes camaradas da pesca. Sem uma atenção às práticas e também às técnicas, boa parte do que esses vigias nos relatam sobre a pesca permaneceria obscuro ${ }^{4}$.

Assim, nossa etnografia esteve atenta principalmente às práticas dos vigias: como olhavam para a paisagem da praia e para o mar, como se posicionavam corporalmente nos postos de vigia, quais os gestos e movimentos que acionavam para falar aos outros camaradas sobre o cardume que avistavam e sobre como colocar a canoa no mar para o cerco, o que comentavam a respeito das mudanças dos ventos, marés e temperatura, o que indicava o sucesso ou fracasso de outros lanços na sua praia ou nas praias vizinhas. Neste caso, era fundamental que aprendêssemos com eles a ver peixe também, ou seja, era preciso um engajamento corporal de nossa parte nesta prática. Essa opção de pesquisa segue o interesse renovado da Antropologia, nas últimas décadas, pela materialidade e pela técnica, pelo corpo e pela percepção como dimensões significativas da vida ${ }^{5}$.

\section{Da Cor da Água às Qualidades Sensíveis: percepção na Antropologia}

Para estimar a quantidade de tainhas no cardume, os vigias referem-se ao tamanho de manchas observadas e de diferenças de tonalidade que indicam a densidade do cardume. Manchas avermelhadas indicam uma manta de milhares de tainhas, enquanto manchas amareladas indicam magotes de centenas de peixes. Essas manchas são melhor observadas a partir de lugares altos, como costões ou palanques erguidos pelos pescadores. Se era muito grande a distância em que se encontravam os cardumes, mesmo quando eles nos apontavam para onde olhar, não conseguíamos observar as mesmas cores que os vigias enxergavam no mar. É difícil discernir essa diferença de tonalidade entre o que seria o amarelo ou o vermelho entre si e com relação a outras mudanças de tonalidade na água do mar causadas por nuvens, ondulações ou materiais no fundo do mar. Aos poucos, os amarelões e os vermelhões passavam a ser mais discerníveis e ainda que não correspondessem ao que conhecíamos por amarelo ou vermelho indicavam uma mudança do azul escuro em direção a tais cores. É possível treinar essa percepção.

Essa é uma questão fundante da Antropologia - por que pessoas têm diferentes percepções do mundo? Será que vemos as mesmas cores? São as cores coisas mentais ou coisas do mundo? Na passagem dos séculos XIX e XX, a percepção foi objeto de interesse e de investigação que levou à conversão para a Antropologia de dois autores centrais na transição para a antropologia moderna ${ }^{6}$, ambos pioneiros na realização de pesquisa de campo, Franz Boas e William Rivers.

\footnotetext{
4 Ver a esse respeito Pink (2009). A autora elabora a ideia de emplaced ethnography para argumentar sobre as formas de conhecer da antropologia que se ocupa dos sentidos e da percepção. O ponto que a autora levanta diz respeito justamente às possibilidades de aprender sobre as percepções dos interlocutores de um lugar situado da prática.

5 Inúmeros trabalhos têm retomado, por caminhos diversos, algumas dessas questões, inspirando-nos diretamente ou indiretamente. Por exemplo, os de Henare, Holbraad e Wastell (2007), Farnell (1999), Csordas (2002), Mol (2002), Latour (2004), Classen (1997), Pink (2009), Howes (2013) e Ingold (2000; 2011).

6 A consolidação institucional por meio da criação de Departamentos de Antropologia, o estabelecimento da pesquisa de campo etnográfica como procedimento de pesquisa e do relativismo cultural como orientação teórica ou paradigma.
} 
Em seu trabalho de doutorado em Física sobre a cor da água, concluído em 1881, Franz Boas levanta questões sobre o efeito do ponto de vista do observador na medição quantitativa dos fenômenos perceptivos. O interesse crescente do autor pela relação entre a experiência perceptual subjetiva e os fenômenos físicos objetivos levou-o a estudar na pós-graduação psicofísica e, depois, geografia, quando realizou a sua primeira experiência de campo, com os Inuit na Ilha de Baffin, nos anos de 1883 e 1884 - experiência determinante para a conversão de Boas à Antropologia (STOCKING JR., 1999 [2004], p. 24-25). O interesse de Boas pela relação entre percepção subjetiva e fenômenos físicos objetivos reaparece no artigo "Sobre sons alternantes" (1889). Nele, o autor afirma, com base em exemplos linguísticos, e também de percepção de formas e cores, "[...] que novas sensações são percebidas com base em experiências perceptivas prévias, sendo classificadas conforme sua similaridade, ainda que diferentes" (BOAS, 1889 [2004], p. 101). É isso que possibilita ou não de as pessoas perceberem diferenças de pronúncia e ainda assim reconhecer que se trata da mesma palavra. As diferenças entre as várias grafias produzidas para as mesmas palavras da língua Inuit resultaria do fato de os estudiosos perceberem e organizarem os sons conforme o sistema fonético da língua inglesa. De maneira semelhante, os falantes de línguas que não possuem um termo específico para a cor "verde" classificariam o que chamamos de "verde" como "azul", mesmo percebendo as diferenças de cor (BOAS, 1889 [2004]).

Por sua vez, William Rivers participou da célebre Expedição ao Estreito de Torres, em 1898, como médico, realizando inúmeros testes com diferentes povos da Austrália e Papua Nova Guiné sobre a acuidade visual, a percepção espacial e de cores, além de ilusões óticas. Dois alunos seus, Charles S. Myers e William McDougall, fizeram testes sobre tempo de reação e sensibilidade tátil, respectivamente (STOCKING JR., 1995). Algum tempo depois, Rivers realizou testes e investigação semelhantes com outros povos, no Canadá, Egito, Ceilão e Índia, sempre com uma perspectiva comparativa, podendo ser considerado o fundador dos estudos transculturais sobre a percepção (DEREGOWSKI, 1998). Embora a conversão definitiva do autor para a antropologia se dê apenas alguns anos mais tarde, essas investigações foram determinantes para tanto (STOCKING JR., 1995, p. 184).

Em comum, Boas e Rivers buscaram recursos na nova psicologia experimental que se desenvolvia no final do século XIX para investigar as diferenças mentais raciais pressupostas pelo pensamento evolucionista da época (STOCKING JR., 1966, p. 872). Todavia, enquanto Rivers buscou explicar a ausência de termos específicos para certas cores em outras línguas em termos de alguma falta de sensibilidade à cor correspondente, apoiando-se e reiterando concepções evolucionistas (STOCKING JR., 1995, p. 186); Boas questionou tais concepções, atribuindo as diferenças mentais a tradições culturais distintas (e não mais a aspectos raciais) (STOCKING JR., 1966, p. 872).

Por uma série de razões, o interesse da Antropologia Social e Cultural pelos fenômenos de percepção diminuiu ao longo do século XX e esses fenômenos acabaram atribuídos a outras áreas do conhecimento, como a psicologia. Na antropologia, o interesse por tais fenômenos foi limitado a círculos bastante restritos e a discussões especializadas - sempre centradas em questões simbólicas e com abordagens fortemente marcadas pelo viés da linguagem. O exemplo fundante e mais notório é aquele dos debates sobre a influência 
ou não da linguagem ( sobretudo, o léxico) na percepção e/ou na memorização de cores Ao longo do século XX, tais debates contrapõem, de um lado, a defesa da influência e da relatividade linguística sobre os processos perceptuais, conforme a chamada hipótese Sapir-Whorf; de outro, uma perspectiva universalista ou antirrelativista que questiona a influência da categorização linguística (D'ANDRADE, 1995).

Em poucas palavras, a grande questão desses debates remete aos efeitos das representações simbólicas sobre a percepção. A discussão antropológica mais geral sobre como diferentes modos de vida - o que chamamos usualmente de cultura - estão relacionados a diferentes modos de percepção é reduzida assim à questão de como e em que medida a linguagem e outras representações culturais influenciam (ou relacionamse com) a percepção, menosprezando outras dimensões da vida social, como as técnicas corporais e as relações práticas com o ambiente.

Voltando ao problema da percepção de cardumes de tainhas a partir da beira da praia, podemos entender que a habilidade de enxergar o "vermelho" ou o "amarelo" no mar opera com um repertório de padrões compartilhado entre os pescadores. Mas é importante não confundir aqui o conceito, a representação do fenômeno, com a experiência da percepção: em cada praia de Florianópolis as condições de observação do mar e as condições ambientais do mar são diferentes tanto estruturalmente (entre baías, praias abertas e costões rochosos, orientados para sul, leste ou norte) quanto em seus ritmos (conforme a incidência de marés, correntes e luz ao longo dos dias) e devem ser levados em conta nesse desenvolvimento da percepção experiente.

Entre a percepção e esse repertório compartilhado de representações, a representação parece ter recebido mais atenção nos estudos antropológicos. Sarah Pink (2009) nos oferece uma breve reflexão sobre esses movimentos de encontros e de desencontros com o tema da percepção e dos sentidos na Antropologia no século XX. A autora situa como um marco importante da retomada deste debate as análises orientadas pela ideia de "corporificação" (embodiment), nos anos 1980 que enfatizaram a importância do corpo como produtor de cultura e não apenas produto dela - por exemplo, Csordas (1990). O questionamento emergente era quanto à arbitrariedade da separação entre mente e corpo. De início, a discussão permaneceu orientada para a análise das diferenças nas percepções sensoriais dos grupos estudados e sua relação com sistemas classificatórios, como fica evidente nas pesquisas de Stoller (1997). Howes (2003; 2005) e Feld (1982). A percepção era analisada, de acordo com Pink (2009), de forma comparativa, em termos das hierarquias entre os sentidos, ou seja, se de um lado a "sociedade ocidental" era percebida como dominada pela visão, "outras sociedades" elegeriam outros sentidos como meio principal de entendimento do mundo.

Em suma, apesar da ênfase no corpo como um agente importante na produção da vida social e não apenas como um suporte para a cultura, a percepção permanece

Tal discussão foi iniciada pelo matemático e classicista britânico William E. Gladstone, em 1858, que atribuiu a limitação do vocabulário para as cores nos escritos homéricos a um senso de cores supostamente distinto daquele que temos hoje. Gladstone pressupunha e estabelecia assim uma relação direta entre o vocabulário para cores e a capacidade para discriminá-las. Anos depois ( 1880 ), o ex-comerciante alemão Lazarus Geiger ampliou tal estudo contemplando escritos antigos nórdicos, semitas, indianos e chineses, levantando também a hipótese de uma ordem comum no desenvolvimento dos vocabulários para cores em diferentes lugares. Tais questóes suscitaram um longo debate que, na antropologia, se inicia com Rivers (1901) e segue, passando por Berlin e Kay (1991). 
subordinada a (e acessada por meio de) representações e valores culturais, dos quais seriam uma forma de expressão. Além disso, Pink (2009) situa a virada reflexiva da disciplina nos anos 1980 - sua atenção ao modo de construção dos textos etnográficos, à dimensão epistemológica de produção do conhecimento e ao debate sobre a representação - como um dos desvios no percurso dos estudos sobre a percepção na Antropologia.

No nosso caso, encontramos um repertório grande de representações sobre as formas das tainhas "se mostrarem" aos vigias, além das já mencionadas mudanças de tonalidades: no ressolho e na aguada, correspondem a padrões perceptíveis de movimento na superfície da água produzidos pelas tainhas em sua passagem. Tais padrões se diferenciam daqueles formados por ondulações e correntes de vento ou produzidos por cardumes de outras espécies. Por exemplo, um cardume de anchovas pode formar uma intensa trepidação na água ao perseguir cardumes de espécies menores, como manjuvas, empurrando-os para a superfície. Tal agitação, por sua vez, atrai aves marinhas em busca das manjuvas, em determinada região discernível no mar. Já o cardume de tainhas produz agitações semelhantes, só que não tão concentradas em um mesmo ponto, espalhadas em uma área maior da superfície. Além disso, ele não atrai aves marinhas, incapazes de carregar as pesadas tainhas, mas eventualmente golfinhos e lobos marinhos.

As diferenças observadas entre estes padrões correspondem a qualidades contrastantes também notadas no comportamento das espécies. As anchovas denunciam sua presença pela voracidade com que se lançam atrás de peixes menores, devendo ser capturadas com uma rede resistente, que restrinja seus movimentos (rede de emalhe). As tainhas são espertas e ligeiras, percebendo facilmente a presença de seus predadores. Por isso mesmo, elas precisam ser cercadas com muito cuidado de modo a impedir uma fuga rápida a qualquer oportunidade.

Os contrastes entre essas qualidades - voracidade e esperteza, agressividade e agilidade - podem servir para pensar outras diferenças observáveis na diversidade marinha, nas relações sociais e alhures. Isso nos remete ao lugar da percepção nas ideias de Lévi-Strauss. Em sua vasta obra dedicada à análise de mitos ameríndios, o autor mostra como pessoas, animais, plantas, astros celestes, fenômenos atmosféricos e formações geológicas, entre tantos outros seres, são 'selecionados' com base em algumas de suas qualidades sensíveis para protagonizar tais narrativas. Nelas, organizados e articulados segundo suas características distintivas, esses entes são mobilizados por meio de analogias e aproximações de modo a produzir sentidos, proposições coerentes e reflexões sofisticadas sobre questões mais ou menos abstratas da vida e do mundo. No mais, expressam um conhecimento acurado do ambiente, provido de coerência e eficiência, resultado de observação exaustiva, experimentação meticulosa e levantamento sistemático de relações entre os fenômenos (LÉVI-STRAUSS, 1962).

Embora o autor tenha argumentando em diversos de seus escritos que há uma correspondência entre as ordens sensível e inteligível (LÉVI-STRAUSS, 1962; 1983; 1988), boa parte das reflexões que se desdobram de sua proposta tendem a concentrar a atenção nas discussões sobre as estruturas mentais e as representações ${ }^{8}$. Para o autor, no entanto, observar as relações das pessoas com o mundo sensível é fundamental para

8 Um conjunto considerável de críticas a Lévi-Strauss concentra-se justamente em afirmar o estruturalismo como essencialmente mentalista. Ver Wiseman (2009). 
a compreensão das estruturas do pensamento humano. Não é à toa que Lévi-Strauss dedica-se a pensar a lógica das qualidades sensíveis como uma dinâmica relacional entre a mente e o mundo, como um processo de mão dupla. Assim, as estruturas imanentes do mundo material se revelam à observação das qualidades sensíveis do ambiente, por meio da percepção, e têm correspondência com as estruturas de pensamento. O autor observa que as diferenças apreendidas do mundo sensível através dos processos perceptivos entre, por exemplo, tipos diferentes de animais ou plantas, possibilitariam elaborar diferenças de outro tipo, relacionadas a diferenças socioculturais. Ocorreria aí o que Lévi-Strauss aponta como uma transformação de "uma coisa" em uma "palavra ou conceito" (WISEMAN, 2009), ou seja, o que está em jogo é um conjunto de relações entre diferenças que estão tanto no mundo material quanto nas estruturas mentais. As condições ecológicas, neste caso, seriam articuladas sistemicamente (LÉVI-STRAUSS, 1983), e a relação entre uma infraestrutura material e as estruturas mentais não se daria em um sentido único, ambos se constituindo simultaneamente. O que talvez possa ser levantado aqui como um ponto crucial para nossa análise é que o conjunto de relações entre diferenças que destaca Lévi-Strauss vai se expressar nos mitos e é esse o material em que o autor está debruçado e que o remete a analisar de forma primordial o pensamento, mais do que as práticas (analisadas sempre de modo subsidiário pelo autor). Nesse sentido, se o processo perceptivo é fundamental para a análise das estruturas mentais, ainda assim o foco de sua atenção está mais voltado para essa lógica relacional do que para a percepção em si.

As qualidades sensíveis são de fato boas para pensar esse sistema de diferenças e entender como um peixe como a tainha percorre o caminho do percepto até o símbolo, a ponto de se tornar um animal identificado com os sentimentos de pertencimento das comunidades pesqueiras ao litoral de Santa Catarina9. Voltaremos a esse ponto, o valor simbólico da tainha, mais adiante. Antes, retomemos a questão da técnica e da percepção. A habilidade dos vigias em perceber os cardumes nas diferenças de padrões de mudanças na paisagem envolve mais do que o repertório de representações. Isso implica uma constante reavaliação dos signos que podem indicar a presença das tainhas, mas também de outros agentes na paisagem local. Uma abordagem teórica relevante para esse debate é aquela de Gregory Bateson (1972), cujo interesse em processos comunicacionais em diferentes fenômenos ${ }^{10}$ nos indica essa presença de sistemas informacionais no mundo, e os constantes processos situados de tradução de diferenças de uma ecologia de energia e matéria em diferenças de uma ecologia de informação que consiste na

\footnotetext{
Diegues (2004), no texto "A pesca construindo sociedades: a história ecológica da tainha no litoral sudeste-sul brasileiro", reúne observações de diferentes pesquisadores a respeito da pesca artesanal da tainha no litoral Sul e Sudeste do Brasil, mostrando como a organização social de coletivos de pesca com esse peixe como espécie-alvo foi responsável pela fixação de comunidades rurais em diferentes localidades no litoral brasileiro, tendo a temporada da tainha como momento de reforço da sociabilidade pesqueira e dos laços de pertencimento a tais comunidades.

10 Bateson observou processos relacionais em diferentes fenômenos como rituais de iniciação masculina entre o povo Iatmul e danças e hábitos corporais entre os Balineses enquanto escrevia situando-se no campo da Antropologia. Posteriormente desenvolveu a análise sistêmica de processos comunicacionais e coevolutivos, tanto no campo da Psicologia quanto da Ecologia, em que abordou desde fenômenos como esquizofrenia, alcoolismo, a comunicação entre mamíferos e a percepção como a relação entre a mente e o mundo nas relações ecológicas entre seres vivos. Em duas de suas últimas duas obras (BATESON, 1972; BATESON; BATESON, 1987) encontramos a inspiração para nossas reflexões sobre a percepção. Diferente de Ingold (2000), optamos aqui por abordar as continuidades entre a abordagem de Lévi-Strauss sobre a lógica das qualidades sensíveis e os processos coevolutivos investigados por Bateson, ao invés de aprofundar as diferenças entre as abordagens desses autores.
} 
percepção (BATESON, 1972; BATESON; BATESON, 1987), que não é exclusividade dos seres humanos. Para Bateson (1972) e para Lévi-Strauss (1983), os objetos no mundo não são percebidos como tais, isto é, como uma realidade física exterior e absoluta, mas sim por meio de sucessivas mediações, relacionadas a propriedades do ambiente, aspectos morfofisiológicos do corpo humano (como os limiares sensoriais), exigências mentais (como as regras de simetria e inversão que operam nos mitos) e orientações culturais particulares (aspectos técnicos e tecnológicos, por exemplo). São tais constrangimentos que determinam quais diferenças particulares, dentre a infinitude de diferenças no mundo, serão percebidas e mobilizadas de modo a produzir sentido. A percepção é, portanto, corporificada e situada, pois determinada por habilidades de percepção situadas nos modos de engajamento dos corpos em ambientes particulares.

O que os vigias percebem, de forma sistêmica, é uma cadeia de signos, em que cada nova diferença inserida na paisagem informa diferentes qualidades da presença, direção, densidade dos cardumes etc. Isso nos indica que a percepção demanda atenção aos aspectos relacionais de sinais presentes na paisagem que são inclusive compreendidos por outros animais marinhos, na medida em que as embarcações, as redes e a movimentação dos próprios pescadores se tornam signo indicial a outros pescadores e às aves que os seguem, da presença dos peixes. Os pescadores têm todo um cuidado em não anunciar sua presença às tainhas (e a outros pescadores) antes de lançar a rede, pois movimentos de embarcações e pessoas podem dispersar os cardumes. As qualidades sensíveis dos peixes são, dessa maneira, revelações a respeito de como se relacionam de uma perspectiva ecológica com o observador e também com outros agentes ambientais.

\section{Habilidades Perceptuais e Técnicas Corporais}

De uma perspectiva ecológica, perceber essas diferenças no ambiente demanda uma forma de engajamento com esse ambiente. No exemplo analisado, os vigias precisam desenvolver um modo de atenção em que buscam esses sinais distribuídos na paisagem. A essa prática, que chamam de "ver peixe", corresponde uma "habilidade perceptual" particular, conforme o conceito de James Gibson (1966). Esse psicólogo estadunidense, que se tornou mais familiar aos antropólogos por meio do trabalho de Tim Ingold (2000; 2011), propôs uma abordagem ecológica para compreensão de comportamentos perceptivos considerando os ambientes no interior dos quais estes ocorrem. Para Gibson, as condições do ambiente não são obstáculos para a percepção dos sinais, mas parte da informação percebida. Nesse sentido, os vigias da tainha não reconhecem os cardumes apesar da ondulação do mar, da turbidez da água e dos reflexos do sol de sombras. Eles "veem peixe" justamente por meio e com esses aspectos do ambiente.

Para desenvolver tal habilidade, percepção e ação não são duas etapas distintas e alternantes da relação do organismo com o ambiente, mas atividades indissociáveis de um mesmo processo de percepção-ação (GIBSON, 1986). É por meio da ação exploratória do organismo no ambiente que este se revela. Tal abordagem nos ajuda a entender que os vigias desenvolvem ao longo da experiência continuada mais do que um repertório de conceitos sobre o comportamento das tainhas, as maneiras de procurar no ambiente tanto 
as recorrências como os padrões de ondulação e iluminação das águas que correspondem às condições atmosféricas e às variações morfológicas das praias, quanto as variações nesses padrões que indicam atividades de outros agentes, em uma cadeia de sinais que podem ser observados dos seus pontos de vigia, que indicam a presença dos cardumes. Percebem não apenas sinais visuais, mas outros sinais sonoros, mudanças de temperatura e direção do vento, entre outros.

Essa é outra contribuição de Gibson que nos ajuda a entender tal técnica. Habilidades perceptuais envolvem a prática com "sistemas perceptuais" (GIBSON, 1966), a operação conjunta de diferentes órgãos e partes do corpo organizados em sistemas perceptuais ativos, que operam segundo combinações variadas. Esses "sistemas perceptuais" correspondem a "modos de atenção", isto é, "formas de orientar o aparato perceptual do corpo" para "procurar e extrair informação sobre o ambiente" (GIBSON, 1966, p. 55). O que envolve ajustes e movimentos exploratórios dos sistemas "olho-cabeça, ouvido-cabeça, narizcabeça e boca-cabeça", além daqueles "cabeça-tronco, tronco-pernas" (GIBSON, 1966, p. 49-51). Esses ajustes não respondem necessariamente a uma intencionalidade que se projeta do pensamento para as práticas, tampouco são resultado de automatismo corporal, mas acontecem no engajamento prático com o ambiente. Tais orientaçõesajustes dos sistemas perceptuais são passíveis de desenvolvimento por meio de uma "educação da atenção". Aprende-se quais posturas, movimentos e gestos precisam ou devem ser realizados para reconhecer as informações no ambiente mais importantes para uma prática específica.

Uma vez que a percepção é realizada por sistemas perceptuais ativos, que correspondem a diferentes disposições posturais e motoras do corpo, nos parece plausível imaginar que tais disposições estejam relacionadas a "técnicas do corpo" (MAUSS, 1935) variadas. Mauss redefine as técnicas (corporais) como modos de agir tradicionais (porque aprendidos e compartilhados socialmente) e eficazes (porque visam produzir um efeito sobre o mundo). Mais importante, o autor redefine o corpo como "[...] o primeiro e o mais natural objeto técnico e, ao mesmo tempo meio técnico do homem" (MAUSS, 1935, p. 407). O corpo é objeto de significação, valoração e ação sociocultural não só porque fazemos coisas sobre ele: tatuagens, escarificações, adornos e vestimentas, projetamos valores e significados. Mas também e, sobretudo, porque produzimos os corpos ao longo de toda a sua ontogenia, desde a concepção do organismo por ocasião e meio do ato sexual entre os genitores, ou da fertilização in vitro ou de outras técnicas de concepção.

Ao longo de toda a vida, regimes dietéticos, posturas e modos de se movimentar, associados ou não a diferentes objetos e em ambientes também culturalmente construídos, exercem influências profundas no desenvolvimento do organismo e em sua constituição corporal: músculos, ossos, tendões, articulações, ritmos e ciclos. Ou seja, o corpo maussiano jamais está pronto ou dado, mas configura-se constantemente na articulação com outros elementos no ambiente. Poderíamos dizer que as técnicas corporais apontam para um vir a ser do corpo, que se estabiliza, individua, em determinadas habilidades para em seguida se desestabilizar e novamente se reorganizar no desenvolvimento destas ou outras habilidades. São formas de fazer, composições bio-psico-sociais (MAUSS, 1935, p. 420) que nos indicam outro caminho para entender os conhecimentos praticados pela 
pesca artesanal. As habilidades perceptuais não são regras que moldam a ação social, mas formas de fazer e transformar pessoas, ambientes e materiais.

Nesse sentido, concordamos com Tim Ingold (2000), quando ele afirma que a variação sociocultural é variação de habilidades, ou seja, se o corpo é um processo em contínuo desenvolvimento, produto e produtor das técnicas corporais, as próprias habilidades e hábitos podem ser pensados como um processo não fixo, embora de tempos em tempos também se individuem em formas mais estabilizadas.

Nesse ponto, gostaríamos de aproximar as técnicas corporais de Marcel Mauss às habilidades de Tim Ingold (2000), mesmo tendo em mente a crítica deste à concepção maussiana de técnica. Ingold considera, de maneira muito abreviada, que Marcel Mauss reduz o conceito de técnica a uma dimensão mecânica, isolando o corpo tanto do ambiente como de sua própria agência ${ }^{11}$. Mesmo que Mauss não reflita sobre o ambiente de forma direta, ou nos termos propostos por Ingold contemporaneamente, isso não significa que veja o corpo isolado de seu entorno ${ }^{12}$. Assim, observamos que os conceitos de técnicas corporais e habilidades são bastante próximos e nos auxiliam a pensar sobre o tema da percepção na Antropologia.

Assim, se Mauss é pioneiro em colocar aos estudos sociais a importância do corpo e as técnicas que o compõe, Ingold avança por considerar as habilidades como modos particulares de percepção e ação, a partir da noção de sistemas perceptuais de Gibson. Sendo a habilidade um modo de perceber que está relacionado aos engajamentos práticos com o mundo e as coisas, a habilidade é também uma forma de conhecer. As habilidades, para Ingold, compõem um sistema de relações em que estão conectados os corpos e o ambiente, ou melhor, corpos e ambientes se "fazem" mutuamente. Nos termos do autor:

We see with eyes trained by our experience of watching what is going on around us, hear with ears tuned by the sounds that matter to us, and touch with bodies that have become accustomed, by the lives we lead, to certain kinds of movement. (INGOLD, 2011, p. 95)

Enfim, com base em uma articulação das noções de "sistemas perceptuais" (Gibson), "técnicas do corpo" (Mauss) e "habilidades" (Ingold), abre-se um caminho para responder à nossa indagação sobre a possibilidade de uma Antropologia da Percepção ${ }^{13}$. Voltando

\footnotetext{
11 "It is that skill cannot be regarded simply as a technique of the body. This was the position advocated in a now classic essay by Marcel Mauss (1979[1934]). Taking his cue explicitly from Plato, Mauss observed that technique does not, in itself, depend upon the use of tools. Song and dance are obvious examples. The dancer, according to Mauss, uses his own body as an instrument; indeed, so do we all, he declares, for the body is surely 'man's first and most natural technical object, and at the same time technical means'. Moreover, in the deployment of these means, the human agent experiences the resulting bodily movements as 'of a mechanical, physical or physico-chemical order' (p. 104). This reduction of the technical to the mechanical is an inevitable consequence of the isolation of the body as a natural or physical object, both from the (disembodied) agency that puts it to work and from the environment in which it operates. To understand the true nature of skill we must move in the opposite direction, that is, to restore the human organism to the original context of its active engagement with the constituents of its surroundings." (INGOLD, 2000, p. 352)

12 Como vimos acima, se para Mauss a aprendizagem é fundamental para o desenvolvimento das técnicas corporais, da mesma forma que os hábitos e posturas adotadas pelos grupos sociais (a razão coletiva, como ele refere), dificilmente podemos considerar que as técnicas para Mauss são elementos puramente mecânicos, sem relação com um contexto de práticas mais amplo, ainda mais se considerarmos a importância que confere à dimensão bio-psico-social dessas técnicas.

13 Interessante notar como tal proposta aproxima-se de ideias da fenomenologia de Merleau-Ponty (1999) e, por caminhos outros, a movimentos mais recentes no seio das ciências cognitivas, em particular, a psicologia cognitiva que atentam para a importância do corpo para os processos cognitivos em geral, dentro os quais a percepção como cognição corporificada (embodied cognition) (GIBBS JR., 2006).
} 
ao nosso problema de pesquisa com os vigias da pesca, nosso esforço tem sido o de nos aproximarmos de suas formas de conhecimento do ambiente costeiro, para entender como conseguem monitorar o movimento dos cardumes de tainhas ao longo da costa. Os vigias comunicam-se com as praias vizinhas e recebem "notícias de peixe" de pescadores situados ao longo de todo o litoral catarinense, o que lhes permite atualizar a cadeia de sinais percebidos na praia a sua frente com informações ecológicas que dão conta de um percurso mais amplo dos cardumes, diferenciando os diversos estados das tainhas durante a temporada, suas transformações entre sua migração para a reprodução até atingirem o tamanho e o sabor ideal da temporada, até os sinais que indicam o final do período e novas mudanças na qualidade do pescado. Muitas vezes ouvimos, junto à sua prática de vigia, comentários sobre as mudanças no vento de Sul para Nordeste, que trariam peixes do Norte, regressando em seu percurso reprodutivo. Ou ao contrário, nova incidência de correntes e ventos de Sul, que trariam os cardumes que foram avistados por pescadores em praias de Laguna, ou mesmo no Rio Grande do Sul, com nova qualidade de peixes, uma variação dentro da mesma temporada de pesca com sabores diferenciados: tainhas mais ou menos gordurosas; com mais ou menos gosto de lama das lagoas; com ovas maiores; ou já desgastadas pelo longo percurso ao regressarem, afetadas por incidências ou ausência de chuvas, tempestades e outros fenômenos ${ }^{14}$. Esses são conhecimentos que partem das técnicas de percepção do ambiente dos pescadores, para então atualizar as conversas nas trocas na praia e nas peixarias locais sobre as qualidades sensíveis do pescado, informações ecológicas nos moldes do que discutimos (DEVOS; BARBOSA; VEDANA, 2019). Aqui, a Antropologia da Percepção nos fornece um outro caminho para entender esses saberes em sua relação com processos de transformação das paisagens costeiras e seus agentes que não são apenas versões culturais de fenômenos naturais já dados. Pelo contrário, tais técnicas, que iniciam na vigia e seguem na captura e no trato com o peixe para consumo ou venda, permitem entender os processos constantes de transformação tanto dos peixes quanto das praias e dos próprios pescadores, a cada nova temporada de pesca.

\section{Do Pesqueiro à Praia e ao Mercado}

Em outra pesquisa etnográfica que realizamos com pescadores artesanais no litoral Nordeste do Brasil, vemos como as habilidades perceptuais podem revelar qualidades sensíveis de outras espécies de peixes associados a outras hidrogeomorfologias. No litoral do Rio Grande do Norte e da Paraíba acompanhamos a pesca de pequena escala com jangadas movidas à vela ou a motor de popa, que acontece no interior da plataforma continental no oceano. Navegando próximo à costa nordestina, no interior de um raio de pouco mais que 12 milhas náuticas, os pescadores conhecem locais relativamente rasos, sobre campos de dunas submersos e recifes de corais, que eles identificam como pesqueiros.

\footnotetext{
14 Algumas dessas variações observadas pelos pescadores são analisadas também por pesquisadores de áreas diversas como a oceanografia e a biologia (VIEIRA; GARCIA; GRIMM, 2008; LEMOS et al., 2014). Porém, como Herbst e Hanazaki (2014) comentam, além de compararem as variações entre as diferentes temporadas, os pescadores estão atentos a variações que acontecem a cada novo evento de uma mesma temporada de pesca.
} 
Para encontrar os peixes ao longo da costa, a navegação da jangada é o modo de chegar até esses pesqueiros, no momento de maior probabilidade de encontrar algumas das espécies-alvo - como as valorizadas ciobas (Lutjanus analis), dentões (Lutjanus jocu) e seus acompanhantes menores, os ariocós (Lutjanus synagris). São peixes cujos juvenis são encontrados em fundos arenosos próximos a estuários, mas que quando adultos tendem a habitar regiões de fundo rochoso em águas próximas à costa, se alimentando de pequenos peixes e de invertebrados. De dia formam pequenos cardumes que se dispersam à noite. É o paradeiro de peixes como esses, de pesqueiro em pesqueiro, que os pescadores procuram, atentos às variações de marés, luminosidade, ventos e correntes oceânicas. A navegação envolve a chamada "marcação por terra corrente", técnica de navegação utilizada para localizar pesqueiros à luz do dia e mantendo a costa à vista. Sentados ou em pé sobre a jangada, deslocando-se em sentido único, o foco de sua atenção alterna-se entre o rumo da jangada e a porção de terra no horizonte, onde se encontram os marcos terrestres que, uma vez alinhados, fornecem o caminho para se chegar aos pesqueiros (BARBOSA; DEVOS, 2017a; 2017b).

Ao partirem, buscam primeiro alinhar a embarcação com dois marcos terrestres, um mais próximo da praia (um farol, uma edificação) que passa a ser visto alinhado a outra elevação mais distantes da costa (uma igreja, torre, árvore, etc.). Seguem essa direção do alinhamento, denominado caminho, até que outro alinhamento se produza com outros dois marcos terrestres, denominado assento, que indica o local de lançar âncora. Uma vez nessa região do pesqueiro, modificam sutilmente o alinhamento do assento, de modo a reposicionar constantemente a embarcação não exatamente em cima, mas na cabeceira do pesqueiro, de modo que a maré conduza os peixes na direção da linha e da isca que será lançada. Foi somente embarcados, na companhia dos jangadeiros, que percebemos que a embarcação nunca está imóvel. A atenção concentra-se no movimento relativo dos marcos terrestres em seu campo visual para realizar ajustes constantes de cabos, velas e demais componentes da embarcação, para encontrar os peixes.

Assim, percebemos que o pesqueiro não é uma coordenada que marca fundos rochosos no litoral, mas o acontecimento de condições ambientais que possibilitam esse encontro da embarcação com os peixes, por meio de certa variação dos movimentos de marés, ventos e correntes. Para realizar esse encontro, a técnica da navegação é a própria ação de percepção dos jangadeiros. O que podemos apreender dessas situações etnográficas é que não se trata apenas de movimento relativo do mundo em relação a um ponto de vista, mas sim de correspondências entre movimentos: movimentos dos corpos, cardumes e ventos, das correntes marinhas e marés, do ciclo e trânsito lunares, das embarcações e linhas de pesca. Uma vez capturados os peixes, outros movimentos também se tornam relevantes aos pescadores, de comerciantes, atravessadores e compradores de pescado, que encontrarão na praia.

Em Baía da Traição (Paraíba), onde começamos a acompanhar as práticas dos jangadeiros, o momento das saídas ao mar para visitação dos pesqueiros e retorno para a terra é determinado sobretudo pelo movimento das marés, que varia diariamente, conforme o ciclo e trânsito lunares. Por isso, pescadores mais experientes de lá afirmam que não basta fazer a "marcação por terra corrente". É preciso também "marcar a maré do peixe", saber em que momento do ciclo da maré os peixes "vêm comer" e podem 
ser encontrados nos pesqueiros. Considerando o tempo que levam de navegação até o pesqueiro, que varia muito conforme a velocidade e direção dos ventos, calculam o momento ideal de chegada até o pesqueiro.

Já em Touros (Rio Grande do Norte), além de estarem atentos à maré do peixe, são calculados os momentos de retorno para a terra, correspondendo aos horários de chegada de consumidores e atravessadores que vêm à praia diariamente para comprar o pescado fresco recém-desembarcado, para consumo em casa, nos restaurantes do entorno ou para transportar e vender nos mercados locais ou de outras cidades. Quem chega primeiro à praia tem melhores condições de venda do seu peixe. Levando em consideração as marés e as condições atmosféricas, os jangadeiros saem para a maré durante a madrugada para retornar à praia no final da manhã, no caso daqueles que pescam nos parrachos, que são os pesqueiros mais próximos da costa, ou à tarde, caso daqueles que se aventuram em pesqueiros mais distantes, as riscas, muitas vezes permanecendo a madrugada toda no mar.

Ao chegarem à praia, as embarcações revelam o conteúdo de suas caixas térmicas e samburás (balaios de cipó ou outros materiais) em que se pode ter uma ideia das espécies de peixes que se encontravam no pesqueiro visitado. Separados os quinhões da tripulação e de outras pessoas que auxiliaram no esforço de pesca (com iscas ou para empurrar a embarcação) passam à venda. Embora tenham maior preço, sobretudo as ciobas e também outros peixes maiores ${ }^{15}$, o pescador costuma dar o seu preço para vendêlos junto com o retalho, os peixes menores, como as mariquitas (Holocentrus ascensionis), cujo sabor é muito apreciado localmente, embora não tenham muito valor comercial. No caso de capturarem uma grande quantidade de ciobas, o pescado segue direto para as peixarias locais ou para os carros dos atravessadores, em que cada espécie é vendida separadamente. Assim, o peixe de cada praia mostra as variações locais da temporada de pesca, a dinâmica de cada pesqueiro e das regiões próximas da costa em que podem ser encontrados. Esse momento de chegada das jangadas e de revelação da captura do dia são a atualização nas notícias das condições ambientais dos pesqueiros próximos ${ }^{16}$.

\section{Habilidades e Agilidades nos Mercados}

É claro que as vendas na beira da praia são muito diversas daquelas que ocorrem nos mercados, que podem ser muito diferentes entre si-pequenos ou grandes, ao ar livre ou fechados, diurnos ou noturnos. No comércio do pescado nos mercados, habilidades perceptivas também orientam a escolha dos peixes. Negociações de preços e quantidades envolvem técnicas corporais que engajam compradores e vendedores em relações com o pescado disponível para a venda e com seu entorno. Olhar, cheirar, tocar, apontar, se aproximar para analisar são alguns dos gestos dos compradores, enquanto vendedores anunciam e mostram seus produtos.

\footnotetext{
${ }^{15}$ Como o peixe serra (Scomberomorus brasiliensis), ou o peixe-galo (Selene setapinnis).

${ }_{16}$ Pelo mesmo motivo, os pescadores artesanais foram protagonistas de várias ações de retirada de toneladas de óleo de praias do Nordeste brasileiro, após o desastre causado pelo vazamento de petróleo cru ao longo de mais de dois mil quilômetros, em mais de 300 localidades do litoral nordestino em 2019. Foram também os pescadores artesanais um dos segmentos mais afetados pelas consequências do desastre pela dificuldade que passaram a ter nessas localidades, tanto para encontrar condições seguras para suas atividades quanto para vender o pescado, cuja característica é a identificação com os ambientes costeiros locais.
} 
O peixe que é negociado na beira da praia, logo após a captura, seguirá seu percurso para as casas de alguns compradores, ou para peixarias, mercados locais e restaurantes, a depender do volume de captura. Em alguns casos, também seguirá para grandes mercados ou mesmo entrepostos comerciais de outros estados. Nesse caminho entre o mar e o consumo, o peixe vai sofrer transformações e se tornar pescado, mercadoria, produto ou comida. Essas transformações são resultado de conjuntos de práticas de manipulação, conservação, beneficiamento e transporte do peixe que envolvem habilidades diversas de pescadores, comerciantes, atravessadores, consumidores em sua relação com a materialidade dos peixes. Habilidades de tratar e armazenar o peixe, de cortar ou "sangrar" determinadas espécies para melhor conservação, de escolher os melhores pescados para expor e vender, de cozinhar e preparar a refeição, entre inúmeras outras, ensejam as transformações dos peixes. O que nosso trabalho de campo tem demonstrado é que tais práticas e habilidades produzem efeitos de individuação do pescado, ou seja, o peixe transita de mercadoria a alimento nas diferentes instâncias de sua cadeia produtiva.

O peixe da praia, sobretudo na pesca da tainha em Florianópolis, Santa Catarina, é um peixe local que tem como valor agregado a emoção de perceber o peixe no mar, de ver o cerco com canoa, de participar do esforço no momento de puxar a rede e trazer o peixe para a areia. A tainha, ao agregar socialidades locais, torna-se alimento valorizado em comunidades litorâneas do Sul e Sudeste do Brasil. Nas trocas que acontecem na praia, o peixe carrega junto consigo partes de relações sociais: as camaradagens no esforço coletivo da pesca quando é usado como pagamento dos pescadores ou de outras pessoas que ajudaram a puxar a rede; os laços de territorialidade das comunidades quanto à sua procedência de cada praia; as qualidades adquiridas em seu trajeto migratório até chegar a cada praia.

Esse peixe local altera seu sabor ao chegar às praias de Santa Catarina, segundo contam os pescadores, pois no caminho dos estuários e lagoas do Sul para o litoral catarinense, a tainha perde o gosto de lama que acumula ao se alimentar do sedimentos e detritos do fundo das lagoas, tendo em vista que no mar sua alimentação muda. Assim, as tainhas que chegam à Barra da Lagoa em Florianópolis já não são as mesmas que saíram da Lagoa dos Patos ou de outros estuários na Argentina, pois são transformadas por seu percurso em direção ao Norte.

O peixe negociado na beira da praia, direto com o consumidor final, poderá ser consumido muito fresco, no mesmo dia ou no dia seguinte. Sai da praia ainda envolto em areia e água salgada, vai logo virar comida, o almoço ou a janta de alguma família. A tainha da Barra da Lagoa (Santa Catarina) pode ser assada em postas ou inteira, frita ou ainda ensopada no feijão. As decisões sobre como cozinhar derivam da análise do peixe adquirido: se é uma tainha grada (mais gorda) e geralmente com ovas, é preferida para o assado; já uma tainha pequena ou mesmo a facão (grande e magra) são preferidas para a frigideira ou ensopado. As ovas da tainha também são bastante apreciadas pelos pescadores e compradores locais, sendo geralmente assadas na brasa ou no forno, podem também ser servidas fritas, com azeite e sal grosso. A qualidade de peixe fresco, recémpescado, evidencia-se no sabor da comida, na textura e firmeza da carne, no cheiro que exala antes e depois de se tornar comida. Comida aqui é pensada não apenas em 
seu aspecto nutritivo, mas social, na medida em que fortalece as relações sociais nessa cadeia de trocas.

Já o pescado destinado ao comércio em mercados e peixarias passará por transformações diferentes e poderá se encontrar com o peixe capturado da pesca industrial. Para estes, o gelo ou a refrigeração cumprem um papel fundamental, que em outros tempos foi também o papel do sal: além de atrasar os eventos físico-químicos e microbiológicos que resultam na deterioração ${ }^{17}$ do peixe, permitindo que ele chegue fresco até o consumidor, também conserva seu brilho e umidade. Podemos pensar o gelo e a refrigeração como mediadores, já que produzem efeitos de evitar certas transformações - a deterioração ao mesmo tempo em que iniciam a transformação do peixe em mercadoria.

O momento em que os peixes chegam às praias e aos portos - seja pela pequena pesca ou pela pesca industrial - é chamado de desembarque tanto pelos comerciantes quanto nas análises da cadeia produtiva do pescado. Nesse desembarque o pescado geralmente é acondicionado em caixas plásticas que podem conter gelo - o suficiente para mantê-los resfriados sem congelar - ou estas mesmas caixas ( sem o gelo) podem ser dispostas em um caminhão frigorífico que irá manter uma temperatura de resfriamento sem congelar os peixes. Os peixes resfriados chegam às peixarias e aos mercados e passam a compor um conjunto com peixes vindos de outros lugares, com frutos do mar de vários tipos, com pescados que já estão lá, muitas vezes congelados e mesmo com outros produtos como temperos, carvão, etc. Ainda que possam guardar a informação de sua origem, o transporte e a conservação por resfriamento exigem do comprador atenção diversa daquela de quem compra na beira da praia. A avaliação sensorial dos atributos do pescado é uma das principais formas de observar a qualidade do peixe ${ }^{18}$. O brilho da pele, dos olhos e das brânquias, firmeza e odor da carne (que deve resistir as marcas da pressão dos dedos), formato dos olhos, são alguns dos indícios das transformações pelas quais passa o peixe no desenrolar da cadeia produtiva. As análises sensoriais e os indicadores de frescor são regulados pelos estados, municípios e por órgãos federais, como a Agência Nacional de Vigilância Sanitária (ANVISA) e o Ministério da Agricultura, Pecuária e Abastecimento (MAPA), a partir de estudos bioquímicos que avaliam as características e os processos de deterioração de cada espécie de peixe, fornecendo instrumentos que permitem a inspeção dos ambientes de venda por fiscais sanitários, como veterinários. No entanto, essas regulações não são necessariamente um roteiro que será seguido pelos compradores como uma lista de controle, e envolve o conhecimento mais amplo dessa cadeia técnica.

Foi na CEAGESP que ouvimos que é "a cadeia de frio" que garante o frescor do pescado, ou seja, a cadeia produtiva do pescado se encontra com a cadeia técnica do gelo e da refrigeração. Na plataforma de vendas de atacado de pescado da CEAGESP, podemos observar o "peixe mercadoria", vendido em grandes quantidades, cada espécie servindo

\footnotetext{
${ }_{17}$ Segundo a pesquisa de Amaral e Freitas (2013, p. 2.094): “Os principais parâmetros intrínsecos que levam à rápida deterioração do pescado fresco estão relacionados com o teor de água intramuscular do pescado (cerca de $80 \%$ ), o pH próximo da neutralidade, à pouca quantidade de tecido conjuntivo, que deixa vulnerável a musculatura aos ataques das enzimas endógenas e à ação microbiana. [...] Pode-se dizer que os fatores extrínsecos, responsáveis por facilitar a degradação do pescado estão relacionados ao tipo de captura, transporte e armazenamento".

18 Além das análises laboratoriais, que se baseiam em amostras e muitas vezes podem ser demoradas, dispendiosas e destrutivas (AMARAL; FREITAS, 2013, p. 2.095).
} 
inclusive como modelo da cotação diária de preços do peixe na comercialização desse produto nos mercados do Estado de São Paulo. Conservar o peixe no gelo ou resfriá-lo não é o mesmo que congelar, são processos distintos que fazem diferença na hora da compra. A decisão sobre resfriar ou congelar também se refere às técnicas de conservação do peixe no que diz respeito ao manejo do estoque, da previsão relacionada ao tipo de mercado para o qual se destina o peixe, bem como sobre seu uso final. A observação das qualidades do pescado é um elemento importante nas relações de compra e venda e geralmente compradores percorrem o apertado espaço da plataforma de pescados da CEAGESP num primeiro momento observando o conjunto dos produtos em exposição para, em seguida se aproximar daqueles que lhes parecem melhores ${ }^{19}$. Daí segue-se uma negociação que envolve analisar de perto alguns dos peixes, pegá-los nas mãos e pressionar a carne, além de cheirar. A observação destas qualidades nos foi ensinada na plataforma da CEAGESP, tanto por comerciantes como por funcionários da instituição com os quais passamos algumas madrugadas de venda de peixes, além de nossa própria observação de como agiam os compradores.

A CEAGESP é um dos mais importantes entrepostos comerciais do mundo. Só a área de atacado de peixes envolve uma relação com 1.500 municípios do país, 22 estados brasileiros e 19 países e se conecta com todas as regiões do Brasil. Em suas dependências circulam diariamente cerca de 50 mil pessoas e 12 mil veículos. Na CEAGESP são comercializadas em média, 200 toneladas/dia de peixes de 97 espécies - os de água salgada representam $60 \%$, cativeiro $30 \%$ e importados 10\%. A CEAGESP possui uma estrutura imensa, abriga prédios administrativos, bem como comércios de lanche e restaurante para uso dos seus trabalhadores e usuários. Conta com galpões de armazenagem de produtos, com uma fábrica de gelo, com lojas de embalagens, com espaços destinados ao beneficiamento do pescado e uma infinidade de outros estabelecimentos que movimentam diariamente o mercado. É um entreposto para hortifrutigranjeiros, pescados e carnes e vende tanto no atacado como no varejo. Nesse texto, quando mencionamos a CEAGESP nos referimos sempre ao atacado do pescado que acontece em duas plataformas também chamadas de pátios - que são espaços cobertos e abertos nas laterais, com um chão de concreto. Durante as madrugadas de terça a domingo, das $2 \mathrm{~h}$ às $6 \mathrm{~h}$ da manhã, encontram-se caminhões frigoríficos de diversas regiões do Brasil bem como de outros países, como Argentina, Chile e Uruguai. Dos caminhões, são descarregadas toneladas de peixes, de diferentes espécies e procedências, de águas doces e salgadas, além de lulas, camarões, caranguejos e diversos outros frutos do mar. Organizados em pilhas de caixas com gelo, fazem emergir uma arquitetura singular para os espaços de venda. Um estreito corredor para a circulação de compradores, vendedores e carregadores surge entre as caixas, enquanto o chão é tomado pela água do gelo que derrete. Diversos odores de peixe misturam-se ao ambiente de sonoridades agressivas das caixas de peixe e gelo que são arrastadas pelo chão, e dos gritos dos carregadores que avisam sobre seus movimentos por estes corredores estreitos.

\footnotetext{
19 Existem também alguns casos de relações de proximidade e preferência entre os comerciantes da CEAGESP e seus clientes que podem influenciar nas escolhas destes últimos, no entanto, durante nosso trabalho de campo, os interlocutores comentavam que a escolha dos peixes baseada apenas nesta relação de proximidade não era comum de acontecer.
} 
Peixes de diferentes lugares circulam rapidamente entre empresas atacadistas, donos de restaurantes, mercados locais e varejistas que adquirem grandes quantidades de produto, além de consumidores finais em busca do pescado para a próxima refeição. Os corpos se deslocam ajustando seus movimentos à cadência dos movimentos coletivos pelos corredores ou então às interrupções que sinalizam o interesse no pescado a ser adquirido. Esses movimentos coordenados também são modos de atenção que possibilitam "ver peixe" e reconhecer suas qualidades como "peixe bom".

Na CEAGESP a qualidade do peixe bom - bom para vender, uma boa mercadoria - se realiza na qualidade da cadeia técnica, que envolve desde o manejo do peixe na pesca e suas formas de armazenamento no barco, até as formas de conservação do pescado que vai ser vendido nas plataformas do entreposto, procedimentos técnicos que devem garantir o sabor e o frescor do peixe para que ele não se torne fraco. A qualidade dessa cadeia técnica está diretamente relacionada com uma série de condições ambientais que indicam os modos de relação com o peixe: a atenção a sazonalidade de determinadas espécies, seus locais de procedência bem como o tempo em que os barcos permanecem no mar são alguns destes aspectos. Na CEAGESP era comum ouvir de comerciantes que também eram donos de barcos de pesca em grande escala sobre suas controvérsias com os pescadores contratados. Enquanto os comerciantes se esforçam para reduzir o tempo do barco no mar, diminuindo por exemplo, a quantidade de insumos e iscas dos pescadores, estes, por sua vez, tendem a alongar o tempo de retorno, buscando maximizar a quantidade pescada. No mercado, peixes da mesma espécie vão chegar então com mais ou menos "tempo no gelo", com mais ou menos força que se tornará perceptível por consumidores mais habilidosos.

Diferentes espécies de peixes demandam também diferentes formas de comercialização. A venda da tainha na CEAGESP é um fenômeno interessante para pensarmos em termos da influência da sazonalidade na sua transformação em mercadoria. Peixes maiores como as ciobas e sobretudo o atum são avaliados em unidades, e com atenção à qualidade de sua carne, podendo seu preço oscilar conforme esses aspectos ${ }^{20}$. Já no caso da tainha, geralmente vendida em grandes quantidades, e conforme a temporada de pesca vai se encerrando, mudam as condições da comercialização. A temporada de pesca oceânica da tainha no Brasil ocorre durante seu ciclo migratório para reprodução, de maio a julho, sendo que a pesca em larga escala (industrial) só ocorre nos meses de junho e julho. Na CEAGESP, as vendas ocorrem entre abril e agosto de cada ano. Em abril e maio a tainha que é vendida é aquela pescada nas lagoas e estuários, tendo as características que já mencionamos (são menores, com menos gordura, sem ovas). Nos meses de junho e julho encontramos os peixes de grandes lanços da pesca artesanal junto com os peixes da pesca de larga escala. São os meses mais promissores em termos de venda do peixe pois, embora os preços sejam mais baixos, a procura é maior, assim como o tamanho

\footnotetext{
${ }^{20} \mathrm{Na}$ CEAGESP observamos que, em peixes como o atum, a forma de avaliar a qualidade do peixe exige que seja possível ver a cor e a textura de sua carne. Lá (como em diversos mercados do mundo), os vendedores introduzem uma sonda embaixo da nadadeira do peixe e retiram um pedaço da carne para atestar sua qualidade. Essa sonda é colocada em direção à parte mais central do peixe, e a coleta da amostra de carne se dá por inserção, quando a sonda é retirada, carrega junto um pedaço da carne do peixe. Essa amostra é colocada sobre um papel branco em cima do peixe e o contraste de cor é o indício de como está o peixe internamente. Quanto mais clara a amostra, mais teor de gordura entremeada está presente no pescado, o produto final (em geral sushis e sashimis em restaurantes japoneses) terá mais sabor e a textura será macia.
} 
dos peixes. Já ao final da temporada, em início de agosto, se houve uma boa safra, ainda há muita tainha de captura recente, com boa qualidade a ser comercializada. É quando a CEAGESP realiza a Festa da Tainha, reproduzindo durante as manhãs, aos finais de semana, nesse imenso entreposto comercial as festas que as comunidades pesqueiras também realizam, comercializando as tainhas por unidade, beneficiadas no momento da comercialização, ou mesmo assadas ou fritas na hora. Por essa sazonalidade marcada por tais formas de comercialização, o conhecimento sobre o ciclo de vida da tainha que mencionamos no início deste texto como parte das relações ecológicas dos pescadores com os peixes, de certa forma reaparece no mercado. Embora se encontrem no mesmo pátio da CEAGESP as tainhas oriundas das capturas artesanais (das praias e pequenas embarcações) com as capturas de larga escala (das traineiras), nas trocas comerciais, os conhecimentos compartilhados sobre essa cadeia técnica do trajeto das tainhas até chegarem aos mercados permitem diferenciar as qualidades e forças de cada captura, na hora de escolher o peixe.

A tainha é apreciada neste momento de sua temporada reprodutiva, quando se reúne em grandes e densos cardumes, atraindo observadores a seu espetáculo de abundância tanto na costa brasileira quanto nos mercados. Mas bem que poderíamos perguntar se não é o contrário que estamos percebendo aqui, algo que mais do que uma preferência cultural, é um reconhecimento de uma agilidade fundamental desse peixe, sua capacidade de provocar densas assembleias, seja no mar, seja na praia, seja no mercado. Agilidade é um conceito que a antropóloga Anna Tsing $(2015 ; 2019)$, inspirada nos escritos de Donna Haraway (2007), nos propõe para entendermos essas habilidades perceptuais de um ponto de vista mais que humano - como outros seres e materiais, neste caso, peixes e pescados, podem ser também sujeitos de práticas sociais em um ponto de vista ecológico, nas relações que constituem a si mesmo e aos ambientes por onde circulam.

\section{Referências}

AMARAL, Gabriela Vieira do; FREITAS, Daniela de Grandi Castro. Método do índice de qualidade na determinação do frescor de peixes. Ciência Rural, Santa Maria, v. 43, n. 11, p. 2.093-2.100, novembro de 2013.

BARBOSA, Gabriel Coutinho; DEVOS, Rafael Victorino. Paralaxe e "marcação por terra": técnicas de navegação entre jangadeiros na Paraíba e Rio Grande do Norte (Brasil). Mana: Estudos de Antropologia Social, Rio de Janeiro, v. 23, n. 3, p. 343-372, 2017a.

BARBOSA, Gabriel Coutinho; DEVOS, Rafael Victorino. Técnicas de navegação por jangadeiros no litoral norte da Paraíba: "marcação por terra", GPS, propulsão à vela e motor". In: SAUTCHUK, C. (ed.). Técnica e Transformação: perspectivas antropológicas. ABA Publicações, 2017b. p. 153-180.

BATESON, Gregory. Steps to an Ecology of Mind. San Francisco: Chandler Pub. Co., 1972 [1987].

BATESON, Gregory; BATESON, Mary Catherine. Angels Fear: Towards an Epistemology of the Sacred. New York: Macmillan, 1987.

BERLIN, Brent; KAY, Paul. Basic color terms: their universality and evolution. Berkeley, California: University of California Press, 1991. 
BOAS, Franz. Sobre sons alternantes. In: STOCKING JR., G. (org.) A Formação da

Antropologia Americana, 1883-1911: antologia Franz Boas. Rio de Janeiro: Contraponto/ Editora UFRJ, 1889 [2004]. p. 98-104.

CLASSEN, Constance. Foundations for an Anthropology of the Senses. International Social Science Journal, [s.l.], v. 153, p. 401-412, 1997

CSORDAS, Thomas. Embodiment as a paradigm to anthropology. Ethos, [s.l.], v. 18, n. 1, p. 5-47, 1990.

CSORDAS, Thomas. Corpo Significado Cura. Porto Alegre: Editora UFRGS. 2002 [2008].

D'ANDRADE, Roy G. The development of cognitive anthropology. Cambridge; New York: Cambridge University Press, 1995.

DERĘGOWSKI, Jan B. W. H. R. Rivers (1864-1922): the founder of research in cross-cultural perception. Perception, [s.l.], v. 27, n. 12, p. 1.393-1.406, 1998.

DEVOS, Rafael Victorino; BARBOSA, Gabriel Coutinho; VEDANA, Viviane. La production du paysage - Pratiques de pêcheurs en bord de mer (Santa Catarina, Brésil). Études rurales, [s.l.], v. 196, p. 57-72, juillet-décembre, 2015.

DEVOS, Rafael Victorino; BARBOSA, Gabriel Coutinho; VEDANA, Viviane. Da temporada da tainha à temporalidade da paisagem. In: MONTARDO, D. L. O.; RUFINO, M. R. C. F. (ed.).

Saberes e Ciência Plural: diálogos e interculturalidade em Antropologia. led. Florianópolis: Editora da UFSC, 2017. p. 173-190.

DEVOS, Rafael Victorino; BARBOSA, Gabriel Coutinho; VEDANA, Viviane. Notícias de peixes: habilidades perceptuais, técnica e cognição distribuída na pesca da tainha. Vibrant: Virtual Brazilian Anthropology, [s.l.], v. 5, n. 16, 2019.

DEVOS, Rafael Victorino; VEDANA, Viviane; BARBOSA, Gabriel Coutinho. Paisagens como panoramas e ritmos audiovisuais: percepção ambiental na pesca da tainha GIS - Gesto, Imagem e Som - Revista de Antropologia, São Paulo, v. 1, p. 41-58, 2016.

DIEGUES, Antonio Carlos Sant'Ana. A pesca construindo sociedades: a história ecológica da tainha no litoral sudeste-sul brasileiro. In: DIEGUES, A. C. S. A Pesca Construindo Sociedades. São Paulo: NUPAUB-USP, 2004. p. 243-315.

FARNELL, Brenda. Moving Bodies, Acting Selves. Annual Review of Anthropology, [s.l.], v. 28, p. 341-373, 1999.

FELD, Steven. Sound and Sentiment: birds, weeping, poetics and song in Kaluli expression. Durham \& London: Duke University Press. 1982 [2012].

GIBBS, JR. Raymond, W. Embodiment in Cognitive Science. New York: Cambridge University Press. 2006.

GIBSON, James J. The Senses considered as Perceptual Systems. Boston: Houghton Mifflin Company, 1966.

GIBSON, James J. The Ecological Approach to Visual Perception. New York: Psychology Press, 1986.

HARAWAY, Donna. When Species Meet. Minneapolis; London: University of Minesota Press, 2007.

HENARE, Amiria; HOLBRAAD, Martin; WASTELL, Sari. Thinking Through Things: theorizing artefacts ethnographically. London: Routledge, 2007.

HERBST, Dannieli Firme; HANAZAKI, Natalia. Local ecological knowledge of fishers about the life cycle and temporal patterns in the migration of mullet (Mugil liza) in Southern Brazil. Neotropical Ichthyology, [s.l.], v. 12, n. 4, p. 879-890, 2014. 
HOWES, David. Sensing Culture: engaging the senses in culture and social theory. Ann Arbor, MI: The university of Michigan Press. 2003.

HOWES, David. (ed.) Empire of the senses: the sensual culture reader. Oxford: Berg. 2005.

HOWES, David. The social life of senses. Ars Vivendi Journal, [s.l.], v. 3. p. 4-23, 2013.

INGOLD, Tim. The Perception of the Environment: essays on livelihood, dwelling and skill. London and New York: Routledge, 2000.

INGOLD, Tim. Being Alive: essays on movement, knowledge and description. London and New York: Routledge, 2011.

LATOUR, Bruno. Como falar do corpo? A dimensão normativa dos estudos sobre a ciência. In: NUNES, J. A.; ROQUE, R. (org.). Objectos Impuros: experiências em estudos sobre a Ciência. [S.l.]: Edições Afrontamento, 2004 [2008]. p. 39-61.

LEMOS, V. M. et al. Migration and reproductive biology of Mugil liza (Teleostei: Mugi- lidae) in south Brazil. Journal of Fish Biology, [s.l.], v. 85, n. 3, p. 671-687, 2014.

LÉVI-STRAUSS. O Pensamento Selvagem. Campinas: Editora Papirus. 1962 [1989].

LÉVI-STRAUSS, Claude. Estruturalismo e Ecologia. In: LÉVI-STRAUSS, Claude. O olhar distanciado. Lisboa: Edições 70, 1983. p. 149-174.

LÉVI-STRAUSS, Claude; ERIBON, Didier. De perto e de longe. São Paulo: CosacNaif. 1988 [2005].

MAUSS, Marcel. As técnicas do corpo. In: MAUSS, Marcel. Sociologia e Antropologia. São Paulo: CosacNaify. 1935 [2005]. p. 399-422.

MERLEAU-PONTY, Maurice. Fenomenologia da percepção. Trad. Carlos A. R. Moura. 2 ed. São Paulo: Martins Fontes, 1999.

MOL, Annemarie. The Body Multiple: ontology in medical practice. Durham and London: Duke University Press. 2002.

PINK, Sarah. Doing Sensory Ethnography. London: Sage, 2009.

RIVERS, William H. R. Primitive Color Vision. Popular Science Monthly, Cambridge University, v. 59, p. 44-58, May, 1901.

STOCKING JR., George W. Franz Boas and the cultural concept in historical perspective. American Anthropologist, New Series, v. 68, n. 4, p. 867-882, Aug. 1966.

STOCKING JR., George W. W. H. R. Rivers: from the evolution of sensory perception to the diffusion of primitive social organization. In: STOCKING JR., George W. After Tylor: British Social Anthropology 1888-1951. Madison: The University of Wisconsin Press, 1995. p. 184-208.

STOCKInG Jr., George W. (org.). A Formação da Antropologia Americana, 1883-1911: antologia Franz Boas. Rio de Janeiro: Contraponto; Editora UFRJ, 1999 [2004].

STOLLER, Paul. Sensuous Scholarship. University of Pennsylvania Press, 1997.

TSING, Anna Lowenhaupt. The Mushroom at the end of the world: on the possibility of life in capitalist ruins. Princeton and Oxford: Princeton University Press, 2015.

TSING, Anna Lowenhaupt. Viver nas ruínas: paisagens multiespécies no Antropoceno. Brasília: IEB Mil Folhas, 2019.

VIEIRA, João Paes; GARCIA, Alexandre Miranda; GRIMM, Alice Marlene. Evidences of El Niño effects on the mullet fishery of the Patos Lagoon estuary. Brazilian Archives of Biology and Technology, [s.l.], v. 51, n. 2, p. 433-440, 2008. 
WISEMAN, Boris. Structure and sensation. In: WISEMAN, Boris. The Cambridge

Companion to Lévi-Strauss. Cambridge: Cambridge University Press, 2009. p. 296-314.

\section{Gabriel Coutinho Barbosa}

Professor no Departamento de Antropologia e no Programa de Pós-Graduação em Antropologia Social (PPGAS) da Universidade Federal de Santa Catarina (UFSC) e pesquisador do grupo CANOA - Estudos em ambientes, percepções e práticas.

Endereço profissional: Departamento de Antropologia, Universidade Federal de Santa Catarina, Campus Trindade, Florianópolis, SC. CEP: 88040-900.

E-mail: ggabrielbar@gmail.com

ORCID: https://orcid.org/0000-0003-0347-9638

\section{Viviane Vedana}

Professora no Departamento de Antropologia e no Programa de Pós-Graduação em Antropologia Social (PPGAS) da Universidade Federal de Santa Catarina (UFSC) e pesquisadora do grupo CANOA - Estudos em ambientes, percepções e práticas.

Endereço profissional: Departamento de Antropologia, Universidade Federal de Santa Catarina, Campus Trindade, Florianópolis, SC. CEP: 88040-900.

E-mail: viviane.vedana@ufsc.br

ORCID: https://orcid.org/0000-0002-1132-5973

\section{Rafael Victorino Devos}

Professor no Departamento de Antropologia e no Programa de Pós-Graduação em Antropologia Social (PPGAS) da Universidade Federal de Santa Catarina (UFSC) e pesquisador do grupo CANOA - Estudos em ambientes, percepções e práticas.

Endereço profissional: Departamento de Antropologia, Universidade Federal de Santa Catarina, Campus Trindade, Florianópolis, SC. CEP: 88040-900.

E-mail: rafaeldevos@yahoo.com

ORCID: https://orcid.org/0000-0001-5985-0155

\section{Como referenciar este artigo:}

BARBOSA, Gabriel C.; VEDANA, Viviane; DEVOS, Rafael V. Habilidades Perceptuais entre a Captura e o Comércio de Pescado. Ilha - Revista de Antropologia, Florianópolis, v. 23, n. 1, p. 153-175, 2021. 